\title{
Shrinking Lung Syndrome Successfully Treated with Rituximab and Cyclophosphamide
}

\author{
Elisabeth Langenskiöld ${ }^{\mathrm{a}}$ Alessandro Bonettic Jean William Fitting ${ }^{\mathrm{a}}$ \\ Raphaël Heinzer $^{a}$ Jean Dudler ${ }^{d}$ François Spertini $^{b}$ Romain Lazor ${ }^{a}$ e \\ Departments of a Respiratory Medicine and ${ }^{\mathrm{b}}$ Immunology, Centre Hospitalier Universitaire Vaudois, and \\ cPrivate Practice, Lausanne, and d Department of Rheumatology, Hôpital Fribourgeois, Fribourg, Switzerland; \\ e Reference Center for Rare Lung Diseases, Louis Pradel Hospital, Hospices Civils de Lyon, Claude Bernard \\ University, Lyon, France
}

\section{Established Facts}

- The treatment of shrinking lung syndrome is not standardized and the efficacy of various treatment modalities is not well established.

\section{Novel Insights}

- Rituximab combined with an immunosuppressive agent may be highly beneficial in shrinking lung syndrome and deserves further study.

- Restoration of near-normal lung function is an achievable goal in shrinking lung syndrome.

\section{Key Words}

Systemic lupus erythematosus $\cdot$ Shrinking lung syndrome $\cdot$ Sjögren syndrome $\cdot$ Rituximab $\cdot$ Cyclophosphamide . Diaphragm $\cdot$ Respiratory paralysis

\section{Abstract \\ Shrinking lung syndrome (SLS) is an uncommon feature of systemic lupus erythematosus (SLE) characterized by dys- pnea, pleuritic chest pain, diaphragmatic elevation, restric- tive ventilatory defect and reduced respiratory muscle strength as measured by volitional tests. We report the case}

of a 28-year-old woman with overlapping features of SLE and Sjögren syndrome who developed severe SLS while receiving corticosteroids and azathioprine for severe polyarthritis. She was treated with a combination of rituximab and cyclophosphamide, which led to a dramatic improvement in her clinical condition and respiratory function tests. The increase in vital capacity was one of the highest among 35 published cases of SLS. Thus, restoring a near-normal lung function is an achievable goal in SLS, and the use of rituximab, with or without concomitant cyclophosphamide, certainly deserves further study in this setting.

Copyright $\odot 2012$ S. Karger AG, Basel

\section{KARGER}

Fax +4161306 1234

E-Mail karger@karger.ch

www.karger.com
(C) 2012 S. Karger AG, Basel

$0025-7931 / 12 / 0842-0144 \$ 38.00 / 0$

Accessible online at: www.karger.com/res
Dr. Romain Lazor

Service de Pneumologie, Centre Hospitalier Universitaire Vaudois

Rue du Bugnon, 46

CH-1011 Lausanne (Switzerland)

Tel. +41 21314 4746, E-Mail romain.lazor@ chuv.ch 
Table 1. Course of respiratory function tests over time

\begin{tabular}{|c|c|c|c|c|c|c|}
\hline Prednisone, mg/day & & 15 & 30 & 30 & 15 & 7.5 \\
\hline Immunosuppressive treatment & & MTX & $\begin{array}{l}\text { switch } \\
\text { MTX } \rightarrow \text { AZA }\end{array}$ & $\begin{array}{l}\text { switch AZA } \rightarrow \\
\text { CYC+RTX }\end{array}$ & CYC+RTX & $\mathrm{RTX}+\mathrm{AZA}$ \\
\hline VC, liters & 3.72 & 3.38 & 2.29 & 1.61 & 2.18 & 2.94 \\
\hline VC drop, $\%$ & & & 46 & 41 & 33 & 18 \\
\hline TLC, liters & 5.23 & 4.42 & 2.36 & NA & 2.54 & 3.71 \\
\hline TLC, \%pred. & & 84 & 45 & NA & 49 & 71 \\
\hline FEV1, liters & 3.25 & 2.92 & 1.59 & 1.24 & 1.63 & 2.38 \\
\hline FEV1, \%pred. & & 89 & 48 & 38 & 50 & 73 \\
\hline $\mathrm{MIP}$ at $\mathrm{RV}, \mathrm{cm} \mathrm{H}_{2} \mathrm{O}$ & $84(>60)$ & & 51 & & 37 & 63 \\
\hline
\end{tabular}

\%pred. = Percent of predicted value; $\mathrm{MTX}=$ methotrexate; $\mathrm{AZA}=$ azathioprine; $\mathrm{CYC}=$ cyclophosphamide; $\mathrm{RTX}=$ rituximab; $\mathrm{TLC}=$ total lung capacity; $\mathrm{FEV}_{1}=$ forced expiratory volume in $1 \mathrm{~s} ; \mathrm{MIP}$ at RV = maximal inspiratory pressure at residual volume; MEP at TLC = maximal expiratory pressure at total lung capacity; VC drop (\%) = VC drop between upright and supine position, expressed in percent of upright VC; SNIP = sniff nasal inspiratory pressure; $\mathrm{P}_{\mathrm{mo}, \mathrm{tw}}=$ twitch mouth pressure by cervical magnetic stimulation; $\mathrm{NA}=$ not available.

\section{Introduction}

Shrinking lung syndrome (SLS) is a rare manifestation of systemic lupus erythematosus (SLE), characterized by dyspnea on exertion, orthopnea, pleuritic chest pain, restrictive ventilatory defect, elevation of both hemidiaphragms, normal lung parenchyma and impaired diaphragmatic strength or activation [1]. Its pathogenesis remains controversial and its treatment is not standardized. Moreover, SLS may appear despite corticosteroid and immunosuppressive therapy given for SLE [2]. We describe a patient with severe SLS receiving prednisone and azathioprine, who was successfully treated with a combination of rituximab and cyclophosphamide. To clarify the efficacy of various treatments in SLS, we reviewed the magnitude of lung function improvements reported in the literature.

\section{Case Report}

A 28-year-old woman presented in February 2009 with acute severe polyarthritis with multiple swollen and painful joints (metacarpophalangeal and proximal interphalangeal joints, wrists, elbows, knees and ankles). Her autoantibody profile showed positive antinuclear antibodies (titer 1/10,240, homogeneous fluorescence pattern), anti-SSA/Ro (166 U) and anti-SSB/ La (46 U). Anticyclic citrullinated peptide and double-stranded DNA were negative. An overlap syndrome was diagnosed, with features of SLE and Sjögren syndrome. Because of invalidating joint pain, she received prednisone up to $30 \mathrm{mg} / \mathrm{day}$, hydroxychloroquine $400 \mathrm{mg} /$ day, and successively methotrexate $15 \mathrm{mg} /$ week and azathioprine $150 \mathrm{mg} /$ day, without any improvement. In March 2009, she was admitted to the intensive care unit for acute pulmonary embolism with transient right heart failure. No antiphospholipid antibodies were detected, and the outcome was favorable with normal lung function tests in April 2009, except for carbon monoxide transfer factor at $66 \%$ of predicted. In August 2009, she developed NYHA III dyspnea, pleuritic chest pain, dry cough and severe orthopnea within a few days. Pulmonary function tests demonstrated the appearance of a severe restrictive ventilatory defect, with a 1.09 -liter (32\%) loss in vital capacity (VC) compared to April. A retrospective examination of consecutive chest X-rays demonstrated progressive elevation of both hemidiaphragms. Chest computed tomography showed neither recurrence of pulmonary embolism nor pleural or interstitial lung disease, and echocardiography ruled out pulmonary hypertension and pericardial effusion. Maximal inspiratory and expiratory pressures, sniff nasal inspiratory pressure and peak cough flow were reduced (table 1), and supine VC showed a 1.05-liter drop $(-46 \%)$ compared to sitting VC. Twitch mouth pressure by cervical magnetic phrenic nerve stimulation was at the lower limit of normal values, and electroneuromyographic studies of peripheral muscles showed no evidence of myopathy. SLS was diagnosed. In 
Table 2. Effect of therapy on VC in 35 cases of SLS

\begin{tabular}{|c|c|c|c|c|c|c|c|c|c|c|}
\hline Case No. & $\begin{array}{l}\text { Initial VC } \\
\text { \%pred. }\end{array}$ & $\begin{array}{l}\text { Final VC } \\
\text { \%pred. }\end{array}$ & $\begin{array}{l}\text { Change in } \\
\text { VC, \%pred. }\end{array}$ & PDN & AZA & $\mathrm{CYC}$ & MTX & RTX & INO & Reference \\
\hline 1 & 22 & 83 & 61 & + & & & & & & 25 \\
\hline 2 & 46 & 100 & 54 & + & & & & & & 4 \\
\hline 3 & 45 & 93 & 48 & + & + & & & & & 29 \\
\hline 4 & 48 & 93 & 45 & + & & & & & & 30 \\
\hline 5 & 43 & 79 & 36 & + & & + & & + & + & present case \\
\hline 6 & 27 & 62 & 35 & + & + & & & & & 25 \\
\hline 7 & 23 & 58 & 35 & + & & & & & & 10 \\
\hline 8 & 36 & 67 & 31 & & & & & & + & 31 \\
\hline 9 & 33 & 62 & 29 & + & & & & & & 32 \\
\hline 10 & 56 & 84 & 28 & + & & & & & & 29 \\
\hline 11 & 52 & 79 & 27 & & & & & & + & 27 \\
\hline 12 & 32 & 59 & 27 & + & + & & & & & 2 \\
\hline 13 & 57 & 83 & 26 & + & & & & & & 30 \\
\hline 14 & 35 & 59 & 24 & + & & & & & + & 33 \\
\hline 15 & 28 & 51 & 23 & + & + & & & & & 2 \\
\hline 16 & 27 & 50 & 23 & + & & & & & & 25 \\
\hline 17 & 45 & 64 & 19 & + & & & & & & 30 \\
\hline 18 & 34 & 52 & 18 & + & & & & + & & 23 \\
\hline 19 & 51 & 67 & 16 & + & & & & & & 25 \\
\hline 20 & 48 & 64 & 16 & + & & & & & & 17 \\
\hline 21 & 38 & 53 & 15 & + & + & & & & & 24 \\
\hline 22 & 40 & 54 & 14 & + & & & & & & 25 \\
\hline 23 & 30 & 44 & 14 & + & & + & & & & 24 \\
\hline 24 & 77 & 88 & 11 & + & & & & + & & 1 \\
\hline 25 & 23 & 34 & 11 & & & & & & + & 28 \\
\hline 26 & 40 & 50 & 10 & + & & & & & & 4 \\
\hline 27 & 63 & 71 & 8 & + & + & & & & & 2 \\
\hline 28 & 49 & 55 & 6 & + & & + & & & & 1 \\
\hline 29 & 33 & 35 & 2 & + & & & + & & & 2 \\
\hline 30 & 69 & 67 & -2 & + & + & & & & & 2 \\
\hline 31 & 40 & 37 & -3 & + & & & & & + & 17 \\
\hline 32 & 45 & 41 & -4 & + & & + & & & & 12 \\
\hline 33 & 40 & 32 & -8 & + & & + & & & & 9 \\
\hline 34 & 67 & 45 & -22 & + & + & & & & & 2 \\
\hline 35 & 64 & 31 & -33 & + & & + & & & & 2 \\
\hline mean $\pm S D$ & $43 \pm 14$ & $61 \pm 19$ & $18 \pm 20$ & & & & & & & \\
\hline
\end{tabular}

Cases have been sorted according to change in VC from highest to lowest value. \%pred. = Percent of predicted value; $\mathrm{PDN}=$ prednisone; $\mathrm{AZA}=$ azathioprine; $\mathrm{CYC}=$ cyclophosphamide; $\mathrm{MTX}=$ methotrexate; RTX = rituximab; INO = inotropic agents $\left(\beta_{2}\right.$-agonists or theophylline); SD = standard deviation.

addition to inhaled long-acting $\beta_{2}$-agonists and theophylline, rituximab, $2 \times 1,000 \mathrm{mg} 2$ weeks apart every 6 months, in combination with cyclophosphamide, $600 \mathrm{mg} / \mathrm{m}^{2}$ every 4 weeks, was introduced, in the hope of controlling both severe polyarthritis and rapidly progressive respiratory deterioration. The treatment induced transient moderate nausea and vomiting, but no hematological, renal or liver toxicity. Self-limited H1N1 infection occurred despite previous vaccination. After 2 cycles of rituximab and 7 cycles of cyclophosphamide, the patient's condition dramatically improved. Dyspnea decreased to NYHA stage II, pleu- ritic pain almost disappeared, lung volumes markedly increased (table 1), and she was in full articular remission without any tender or swollen joints. Rituximab was continued, while cyclophosphamide was replaced by azathioprine, $150 \mathrm{mg} / \mathrm{day}$, and prednisone was tapered to $7.5 \mathrm{mg}$ /day.

To compare the effectiveness of the present treatment with previously reported modalities, we reviewed 35 published cases of SLS with available lung function before and after therapy (table 2). The mean VC was $43 \pm 14 \%$ of predicted before treatment, and $61 \pm 19 \%$ of predicted after treatment. The mean change in VC 
under therapy was $18 \pm 20 \%$ of predicted (range +61 to $-33 \%$ of predicted). With an increase in VC of $36 \%$ predicted, our case experienced one of the highest improvements reported so far. A return to a normal VC ( $>80 \%$ of predicted) was achieved in only $20 \%$ of cases.

\section{Discussion}

We describe a patient who developed severe SLS despite ongoing corticosteroid and azathioprine treatment, for which we chose to administer a combination of rituximab and cyclophosphamide, both to control joint involvement and treat SLS, a potentially lethal respiratory condition. The dramatic respiratory improvement observed (VC $+36 \%$ of predicted) under this treatment was among the highest reported so far. This case demonstrates that restoration of near-normal lung function is an achievable goal in SLS although it has been previously observed in only a minority of cases.

SLS is a rare complication of SLE, with an estimated prevalence of $0.5-1 \%$ in the whole SLE population [3], and has also been described with other autoimmune disorders, such as rheumatoid arthritis, Sjögren syndrome and systemic sclerosis [4-6]. In the present case, SLS developed in a patient with overlapping features of SLE and Sjögren syndrome. The pathogenesis of SLS is unclear. Most authors have documented a restrictive ventilatory defect in the absence of interstitial lung disease, elevated hemidiaphragms on chest X-ray, and decreased values of volitional tests of inspiratory muscle strength such as maximal inspiratory pressure, sniff nasal inspiratory pressure, and maximal transdiaphragmatic pressure, suggesting a myopathic process $[1,2$, 7-10]. In contrast, Laroche et al. [11] reported a normal maximal transdiaphragmatic pressure during bilateral electric phrenic nerve simulation in all of 10 patients tested, suggesting a failure of diaphragm activation rather than intrinsic myopathy. Phrenic nerve palsy was reported in 2 isolated cases of SLS [12, 13], but no evidence of demyelinating phrenic neuropathy was found in all 9 subjects tested by Wilcox et al. [14]. As pleural involvement is common in SLE, it was suggested that SLS may be caused by pleural adhesions [8]. However, SLS has not been observed in patients with pleural adhesions of other origin, and necropsy of 1 patient with SLS showed diaphragm fibrosis and atrophy without any inflammation or pleural adhesion [15]. More recently, the hypothesis of an inhibitory intercostal-phrenic and phrenic-to-phrenic reflex caused by pleural inflammation and pain has been suggested [1]. Indeed, pleuritic pain is a prominent feature in $65 \%$ of patients with SLS [1] and an inhibitory reflex could explain diaphragm dysfunction during spontaneous breathing and voluntary maneuvers, in the absence of muscle weakness. Most authors currently believe that SLS is due to multiple pathogenic mechanisms.

Although the mortality of SLS appears to be low, it may lead to significant disability [16]. Some patients only experience improvement in symptoms but no change in lung function [2]. It has even been suggested that the perceived improvement could result more from the patient's adaptation to his or her limited functional capacity rather than to a real improvement [10]. The present review of 35 evaluable cases of SLS shows that only $20 \%$ recuperate a normal VC, challenging the common belief that SLS has a good prognosis.

Due to its rarity and uncertainty about its cause, the treatment of SLS is not standardized. Several reports describe the efficacy of variable doses of corticosteroids, either alone or combined with azathioprine, cyclophosphamide or methotrexate $[1,2,7,10,13,17]$. Anecdotic reports suggest a modest benefit of theophylline and $\beta$ agonists [7].

Rituximab is an anti-CD20 monoclonal antibody leading to specific $\mathrm{B}$ cell depletion by decreasing differentiation of pre-B cells to plasmocytes. First approved for treating B-cell lymphomas, rituximab is increasingly used in severe and refractory autoimmune disorders, with the aim to decrease autoantibody production and disease activity [18]. In SLE and Sjögren syndrome, the two conditions overlapping in our patient, data on the efficacy of rituximab appear conflicting. A double-blind randomized placebo-controlled trial showed the effectiveness and safety of rituximab in patients with primary Sjögren syndrome [19]. In contrast, two large phase II/III randomized placebo-controlled trials failed to show any clinical benefit from rituximab in patients with moderate to severe SLE $[20,21]$. Potential explanations might have been an overrepresentation of moderate forms with mucocutaneous and musculoskeletal involvement, insufficient follow-up time, and/or concomitant use of high doses of corticosteroids [22]. The use of rituximab has been reported in only 2 cases of SLS, both of which were associated with SLE. Both patients achieved near-normal lung function after 9 month and 2 years, respectively $[1,23]$. One of these cases was refractory to cyclophosphamide [1]. Given the unclear mechanism of SLS, and the conflicting data on the efficacy of rituximab in different autoimmune diseases associated with SLS, the way in which B-cell depletion improves this condition is uncertain. 
Cyclophosphamide induces death of replicating cells by inhibiting DNA transcription. It is considered standard therapy for several aggressive autoimmune diseases, including SLE nephritis. Cyclophosphamide use has been reported with variable efficacy in a few cases of SLS, usually in patients with severe SLE, and after failure of other treatments $[1,2,9,12,24]$. The rationale for its use in SLS is based on the hypothesis of phrenic nerve neuropathy due to vasculitis of vasa nervorum, or immune complex- or autoantibody-mediated injury [25]. Interestingly, it has been suggested that cyclophosphamide could increase the effectiveness of rituximab by making B cells more susceptible to lysis, thus achieving a higher level of depletion [26].
The combination of rituximab and cyclophosphamide used in the present case appeared to be particularly effective as compared to other published data (table 2). This result was achieved in spite of the initial severity of lung function impairment. Considering the slowly progressive response, the role of inotropic agents is believed to have been minor whereas a rapid response within a few days should have occurred if these agents had been effective $[27,28]$. Although the respective input of rituximab and cyclophosphamide in the improvement in the patient's condition cannot be precisely determined, this combination appeared to be highly effective in the present case and deserves further study. It also demonstrates that significant improvement in lung function is an achievable goal in SLS, and suggests that therapeutic strategy should aim at restoring a normal functional capacity.

\section{References}

$>1$ Toya SP, Tzelepis GE: Association of the shrinking lung syndrome in systemic lupus erythematosus with pleurisy: a systematic review. Semin Arthritis Rheum 2009;39:30 37.

-2 Karim MY, Miranda LC, Tench CM, Gordon PA, D'Cruz DP, Khamashta MA, Hughes GR: Presentation and prognosis of the shrinking lung syndrome in systemic lupus erythematosus. Semin Arthritis Rheum 2002;31:289-298.

-3 Pego-Reigosa JM, Medeiros DA, Isenberg DA: Respiratory manifestations of systemic lupus erythematosus: old and new concepts. Best Pract Res Clin Rheumatol 2009;23:469480.

4 Ahmed S, Herrick A, O’Driscoll BR: Shrinking lung syndrome in patients without systemic lupus erythematosus: comment on the concise communication by Tavoni et al. Arthritis Rheum 2001;44:243-245.

5 Scire CA, Caporali R, Zanierato M, Mojoli F, Braschi A, Montecucco C: Shrinking lung syndrome in systemic sclerosis. Arthritis Rheum 2003;48:2999-3000.

6 Tavoni A, Vitali C, Cirigliano G, Frigelli S, Stampacchia G, Bombardieri S: Shrinking lung in primary Sjögren's syndrome. Arthritis Rheum 1999;42:2249-2250.

$>7$ Warrington KJ, Moder KG, Brutinel WM The shrinking lungs syndrome in systemic lupus erythematosus. Mayo Clin Proc 2000; 75:467-472.

$>8$ Gibson CJ, Edmonds JP, Hughes GR: Diaphragm function and lung involvement in systemic lupus erythematosus. Am J Med 1977;63:926-932.

$>9$ Hawkins P, Davison AG, Dasgupta B, Moxham J: Diaphragm strength in acute system- ic lupus erythematosus in a patient with paradoxical abdominal motion and reduced lung volumes. Thorax 2001;56:329-330.

10 Hoffbrand BI, Beck ER: 'Unexplained' dyspnoea and shrinking lungs in systemic lupus erythematosus. Br Med J 1965;i:1273-1277.

11 Laroche CM, Mulvey DA, Hawkins PN, Walport MJ, Strickland B, Moxham J, Green M: Diaphragm strength in the shrinking lung syndrome of systemic lupus erythematosus. Q J Med 1989;71:429-439.

12 Hardy K, Herry I, Attali V, Cadranel J, Similowski T: Bilateral phrenic paralysis in a patient with systemic lupus erythematosus. Chest 2001;119:1274-1277.

13 Al-Raqum HA, Uppal SS, Al-Mutairy M, Kumari R: Shrinking lung syndrome as a presenting manifestation of systemic lupus erythematosus in a female Kuwaiti. Clin Rheumatol 2006;25:412-414.

14 Wilcox PG, Stein HB, Clarke SD, Pare PD, Pardy RL: Phrenic nerve function in patients with diaphragmatic weakness and systemic lupus erythematosus. Chest 1988;93:352358.

15 Rubin LA, Urowitz MB: Shrinking lung syndrome in SLE - a clinical pathologic study. J Rheumatol 1983;10:973-976.

-16 Ernest D, Leung A: Ventilatory failure in shrinking lung syndrome is associated with reduced chest compliance. Intern Med J 2010;40:66-68.

17 Cavallasca JA, Dubinsky D, Nasswetter GG: Shrinking lungs syndrome, a rare manifestation of systemic lupus erythematosus. Int J Clin Pract 2006;60:1683-1686.

18 Bertsias GK, Salmon JE, Boumpas DT: Therapeutic opportunities in systemic lupus erythematosus: state of the art and prospects for the new decade. Ann Rheum Dis 2010;69: 1603-1611.

19 Meijer JM, Meiners PM, Vissink A, Spijkervet FK, Abdulahad W, Kamminga N, Brouwer E, Kallenberg CG, Bootsma H: Effectiveness of rituximab treatment in primary Sjögren's syndrome: a randomized, doubleblind, placebo-controlled trial. Arthritis Rheum 2010;62:960-968.

20 Merrill JT, Neuwelt CM, Wallace DJ, Shanahan JC, Latinis KM, Oates JC, Utset TO, Gordon C, Isenberg DA, Hsieh HJ, Zhang D, Brunetta PG: Efficacy and safety of rituximab in moderately-to-severely active systemic lupus erythematosus: the randomized, double-blind, phase II/III systemic lupus erythematosus evaluation of rituximab trial. Arthritis Rheum 2010;62: 222-233.

21 Furie R, Looney RJ, Rovin B, Latinis KM, Appel G, Sanchez-Guerrero J, Fervenza FC: Efficacy and safety of rituximab in subjects with active proliferative lupus nephritis: results from the randomized, double-blind phase III lunar study. Arthritis Rheum 2009; 60:S429.

22 Lateef A, Petri M: Biologics in the treatment of systemic lupus erythematosus. Curr Opin Rheumatol 2010;22:504-509.

23 Benham H, Garske L, Vecchio P, Eckert BW: Successful treatment of shrinking lung syndrome with rituximab in a patient with systemic lupus erythematosus. J Clin Rheumatol 2010;16:68-70.

24 Elkayam O, Segal R, Caspi D, Yaron M, Greif Y: Restrictive lung disease due to diaphragmatic dysfunction in systemic lupus erythematosus. Two case reports. Clin Exp Rheumatol 1992;10:267-269. 
25 Oud KT, Bresser P, ten Berge RJ, Jonkers RE The shrinking lung syndrome in systemic lupus erythematosus: improvement with corticosteroid therapy. Lupus 2005; 14:959_ 963.

26 Leandro MJ, Edwards JC, Cambridge G, Eh renstein MR, Isenberg DA: An open study of $B$ lymphocyte depletion in systemic lupus erythematosus. Arthritis Rheum 2002;46: 2673-2677.

27 Van Veen S, Peeters AJ, Sterk PJ, Breedveld FC: The 'shrinking lung syndrome' in SLE, treatment with theophylline. Clin Rheumatol 1993;12:462-465.
28 Thompson PJ, Dhillon DP, Ledingham J, Turner-Warwick M: Shrinking lungs, diaphragmatic dysfunction, and systemic lupus erythematosus. Am Rev Respir Dis 1985;132: 926-928.

29 Stevens WM, Burdon JG, Clemens LE, Webb J: The 'shrinking lungs syndrome' - an infrequently recognised feature of systemic lupus erythematosus. Aust NZ J Med 1990;20:6770.

30 Soubrier M, Dubost JJ, Piette JC, Urosevic Z, Rami S, Oualid T, Ristori JM, Bussiere JL: Shrinking lung syndrome in systemic lupus erythematosus. A report of three cases. Rev Rhum Engl Ed 1995;62:395-398.
Munoz-Rodriguez FJ, Font J, Badia JR, Miret C, Barbera JA, Cervera R, Ingelmo M: Shrinking lungs syndrome in systemic lupus erythematosus: improvement with inhaled $\beta$-agonist therapy. Lupus 1997;6:412-414.

32 Walz-Leblanc BA, Urowitz MB, Gladman DD, Hanly PJ: The 'shrinking lungs syndrome' in systemic lupus erythematosus improvement with corticosteroid therapy. J Rheumatol 1992;19:1970-1972.

33 Branger S, Schleinitz N, Gayet S, Veit V, Kaplanski G, Badier M, Magnan A, Harle JR: Le syndrome des poumons rétractés et les maladies auto-immunes. Rev Méd Interne 2004; 25:83-90. 